\title{
Divulgación:
}

\section{Discurso inaugural de la Semana de la Carrera de Física}

\author{
Alejandro Galo Roldán ${ }^{1}$ \\ ${ }^{1}$ Universidad Nacional Autónoma de Honduras, mail: alejandrogaloroldan@gmail.com
}

La Física, por su naturaleza de enfocar los fenómenos en sus causas más básicas, es entonces también capaz de dar un sustento a la explicación de todos los demás fenómenos de la otras Ciencias Naturales. Nadie niega que la química y la biología tienen su propio estamento y su propia legalidad, sin embargo las leyes primarias son las de la Física. La reacciones químicas entre átomos y moléculas tiene leyes establecidas en la química pero al final de cuentas son fenómenos que en su más profunda intimidad corresponden a intercambios de materia y energía entre partículas elementales, no son más que manifestaciones de los principios de conservación de masa, carga y energía y no son más que hermosas manifestaciones de la segunda ley de la termodinámica.

Los esplendidos y complejos sistemas biológicos también son, en sus profundas causas, explicados por leyes físicas, aunque los ciclos biológicos son regulados por principios de la bioquímica y de la fisiología, al final de cuenta, son moléculas interactuando por fuerzas electromagnéticas y evolucionando de acuerdo a la ecuación de Schrödinger.

Por esas razones, a los que nos gusta ver la fenomenología desde sus perspectivas filosóficamente más fundamentales, estudiamos física, sin embargo este es un compromiso serio que no puede ser abordado con tibieza. La Física requiere fanáticos, personas que sean capaces de entregarse en cuerpo y alma a la disciplina sin escatimar esfuerzos. No se puede ser un físico a medio tiempo, ser físico requiere de un trabajo duro. La Física requiere la curiosidad de un niño, la pasión de un artista y la disciplina de un soldado.

La historia de hacer un esfuerzo sistemático comenzó en Honduras y específicamente en la UNAH en el año de 1967 cuando fue creada la carrera de física en el grado de licenciado. En 1969 ingresaron los primeros estudiantes a la carrera de física y bajo el esquema de incorporación de los estudios de bachillerato universitario en la UNAH, estos estudiantes se graduaron de BS (Bachiller Universitario) en 1976.

Se puede mencionar en este primer grupo de estudiante, entre otros a: Daniel López, Jorge Fúnez, Carlos Rodríguez y a Juan Carlos Reyna, y entre los profesores que dieron sustento académico a este grupo podemos mencionar al ingeniero Francisco Antúnez, al Dr. Marco A Zúñiga (Q.E.P.D.) y al Dr. Cesar Rodríguez. Posteriormente se graduaron otros bachilleres universitarios en Física, entre los que están: Daysi Rodríguez, Francisco López, Roberto Fajardo, Guido Velasquez y Herlan Bonilla. Con la incorporación al departamento de física en 1975 del entonces MSc. Gustavo Pérez y en 1976 de los entonces MSc. Gonzalo Cruz (Q.E.P.D.) y Armando Euceda, fue que la carrera comenzó a encaminarse por los derroteros de los cuales nosotros ahora podemos ser testigos. Fue así como se graduaron nuevos bachilleres, entre ellos Gilberto Lezama y Jorge Guzman, pero fue hasta el año de 1986 cuando el entonces bachiller universitario en física Roberto Fajardo Murillo, se convirtió en el primer graduado de licenciado en física en una universidad hondureña.

Hubo un tiempo de receso, y entre 1991 y 1992 bajo la coordinación de este servidor en la carrera de física obtuvieron su título de licenciados en física, después de sustentar sus tesis, Pablo Domínguez, Maximino Suazo y Manuel Rodríguez Vega.

En años siguientes vinieron otro grupo de graduados: Marco flores, José Reyes, Elisabeth Espinoza, Carlos Tenorio, José Jorge Escobar, Werner Stolz, Marco Antonio Reyes y Jackie Saadeh. Varios de ellos fueron producto, a mucho orgullo, de su servidor, del profesor Roberto Fajardo, de los profesores Edwin Romell Galo y Felipe Garay y también, por supuesto, de la vieja camada de profesores.

Pese a todo lo antes descrito en el decenio de 1990 al 2000 la carrera de física era una carrera sumamente pequeña y de unos pocos graduados. Fue hasta a inicios del presente siglo que se comenzaron a sentir los efectos del trabajo sistemático del profesor Gustavo Ponce, quien había llegado a Honduras en 1989, y quien por su pasión y entusiasmo y gran capacidad de convencimiento, comenzó a arrastrar a un grupo de alumnos, hacia la carrera, hasta ver la realidad que tenemos ahora, secciones de 20 alumnos en las clases profesionalizantes, situación que ni en sueño pasaba por nuestra mente hace 20 años. Pero no solo es cantidad, es calidad, tenemos graduados nuestros exportados a México, 
Alemania, España, Australia y Brasil y esperamos que ese número vaya en aumento.

Es oportuno dar también un reconocimiento al profesor Nabil Kawas quien con su extraordinaria gestión ha logrado que varios de los que fueron y ahora son profesores en esta carrera pudierán hacer sus estudios en el exterior, sobretodo en el área de ciencias de la tierra.

Se ha hecho bastante, sin embargo hay todavía mucha tela que cortar, el plan de estudios actual es vigente desde 1994 y es obvio que ya entró en obsolescencia. En la actualidad y gracias al gran trabajo del profesor Felipe Garay, ayudado por la subcomisión curricular de la carrera, se ha logrado presentar la propuesta de la reforma, conteniendo la misma un plan más actualizado, dinámico y de acuerdo a los recursos tecnológicos con que cuenta la disciplina para desarrollarse. Esperamos que las instancias que tienen que dictaminar finalmente aceleren este paso para poder comenzar a utilizar este nuevo curriculum.

Es en este contexto histórico es que los estudiante de la carrera de Física han organizado, en esta semana del 8 al 12 de Junio, de manera muy eficiente, una serie de actividades, científicas, culturales y deportivas, con el fin de conmemorar grandes descubrimientos, difundir tecnologías de punta y dar a conocer avances en la disciplina, pero todo esto en una marco de camaradería y salpicado con actividades lúdicas que fortalecen el cuerpo y el espíritu.

Quiero felicitar a la junta directiva de la Asociación de alumnos por su gran capacidad de liderazgo mostrado en la organización de este evento y también a todos los alumnos por el apoyo que han brindado en distintas formas.

Al mismo tiempo agradecerles por el reconocimiento hacía mi persona por haber bautizado con mi nombre esta primer semana, sinceramente creo que el mismo es inmerecido porque estoy seguro que hay personas que lo merecen mas que yo, pero lo acepto con humildad y con el compromiso de seguir siempre con mi voluntad de servicio y tratando de poner todo nuestro empeño porque las cosas se hagan bien hechas.

Para finalizar, no me queda más que decirles que me siento orgulloso de esta juventud y que hoy tengo menos dudas en que ellos serán los que marquen el punto de inflexión para que definitivamente logremos que la física alcance el nivel de desarrollo necesario para así poder alimentar nuevos descubrimientos y desarrollos tecnológicos propios, mismos que son la condición básica para salir del atraso en que nos encontramos. 